\title{
Type II Total Anomalous Pulmonary Venous Return
}

National Cancer Institute

\section{Source}

National Cancer Institute. Iype II Total Anomalous Pulmonary Venous Return. NCI

Thesaurus. Code C98592.

Total anomalous pulmonary venous return in which the pulmonary veins drain into the right atrium via the coronary sinus. 